\title{
Transforming Growth Factor Beta Measurement
}

National Cancer Institute

\section{Source}

National Cancer Institute. Transforming Growth Factor Beta Measurement. NCI

Thesaurus. Code C122155.

The determination of the amount of total transforming growth factor beta in a biological specimen. 